\title{
Neonate with Rare Clinical Presentation of COVID-19: A Report of Two Clinically Distinct Cases
}

\author{
Ruma Parvin ${ }^{1}$, Sharmin Afroze ${ }^{2}$, AHM Khairul Bashar ${ }^{3}$, Sheikh Farjana Sonia ${ }^{4}$, Nobo Krishna \\ Ghosh $^{5}$
}

${ }^{1}$ Associate Professor, Dr. MR Khan Shishu Hospital \& Institute of Child Health, Dhaka, Bangladesh; ${ }^{2}$ Assistant Professor, DR. MR Khan Shishu Hospital \& Institute of Child Health, Dhaka, Bangladesh; ${ }^{3}$ Assistant Professor, Sylhet MAG Osmani Medical College, Sylhet, Bangladesh; ${ }^{4}$ Assistant Professor, DR. MR Khan Shishu Hospital \& Institute of Child Health, Dhaka, Bangladesh; ${ }^{5}$ Professor, DR. MR Khan Shishu Hospital \& Institute of Child Health, Dhaka, Bangladesh

[Received: 12 July 2020; Accepted: 30 August 2020; Published: 1 December 2020]

\begin{abstract}
Coronavirus disease 2019 (COVID-19), caused by severe acute respiratory syndrome coronavirus 2 (SARS-CoV-2), has spread across the world. We describe two cases of neonate, presenting with features like multisystem inflammatory syndrome (MIS-C), who presented to our neonatal unit of Dr. M R Khan Shishu Hospital, Bangladesh on August, 2020.Case 1 was a 7-day-old male infant presented at 14 hours of life with fever, poor feeding, per rectal bleeding and shock. Detailed examination revealed Down's fancies and pallor. Case 2 was 15-day old neonate presenting with fever, rash and convulsion and his laboratory values were remarkable for high levels of C-reactive protein, D-dimer, ferritin and his Cerebrospinal fluid (CSF) findings were consistent with aseptic meningitis. Both babies were tested positive for severe acute respiratory syndrome coronavirus 2 (SARS-CoV-2). First case was very critical and referred to tertiary care hospital after stabilization. $2^{\text {nd }}$ case recovered completely and was discharged to home in 15 days. Though till date COVID 19 in neonate is not very well-known to us, it is essential to disseminate information among the medical community regarding severe and atypical presentations of COVID-19 in neonate as prior knowledge can help to quickly identify and treat these patients as they present in the neonatal department. [Bangladesh Journal of Infectious Diseases, December 2020;7(2):102-106]

Keywords: Covid-19; neonate; shock; aseptic meningitis

Correspondence: Dr. Ruma Parvin, Associate Professor, Dr. MR Khan Shishu Hospital \& Institute of Child Health, Mirpur, Dhaka, Bangladesh; Email: ziaruma66@yahoo.com; Cell no.: +8801711119127

Conflict of interest: The authors declared no conflict of interest.

Funding agency: This case report did not receive any special funding.

Contribution to authors: Conception: Parvin R, Afroze S; Collection and assembly of data: Bashar AHMK, Sonia SF; Writing manuscript: Parvin R; Editing and approval of final draft: Ghosh NK

How to cite this article: Parvin R, Afroze S, Bashar AHMK, Sonia SF, Ghosh NK. Neonate with Rare Clinical Presentation of COVID-19: A Report of Two Clinically Distinct Cases. Bangladesh J Infect Dis 2020;7(2):102-106

Copyright: (92020. Parvin et al. Published by Bangladesh Journal of Infectious Diseases. This article is published under the Creative Commons CC BY-NC License (https://creativecommons.org/licenses/by-nc/4.0/). This license permits use, distribution and reproduction in any medium, provided the original work is properly cited, and is not used for commercial purposes.
\end{abstract}




\section{Introduction}

The corona virus disease 2019 (COVID-19) caused by the severe acute respiratory syndrome corona virus 2 (SARS-CoV-2) is a global public health threat $^{1}$. SARS-CoV-2 infection has recently been associated with a novel set of clinical manifestations presently called multisystem inflammatory syndrome in children (MIS-C) that is beginning to be recognized in the United States, although published reports from the United States are lacking ${ }^{2}$. Reports of neonatal cases are sparse, posing many unanswered questions on the disease characteristics of COVID-19 in this population. However a new and potentially life threatening condition that many pediatricians may not be aware. Herein we report two cases of SARS-CoV-2 related MIS-C observed at end of august 2020.

\section{Case 1}

A 7-day-old male infant of an unrelated couple presented with a one-day history of per rectal bleeding and poor feeding. Mother (gravid 4, Para 4) was on irregular antenatal check-up but had an uneventful antenatal course. She had no history of fever, cough, rash or prolonged rupture of membranes. The infant was born via vaginal delivery at 39 weeks of gestation without complications. Breastfeeding was started but at 6 days of life the baby became lethargic, could not feed properly and developed per rectal bleeding. Mother had no history of contact to a COVID-19 patient or symptomatic acquaintances. On physical examination, the baby was hypotonic, pale, febrile (temperature was $\left.100^{\circ} \mathrm{F}\right)$, tachycardic (HR169/min), tachypnic (RR-66/min), and had dysmorphic facies suggestive of Down's syndrome (wide open fontanel, microcephaly, flatocciput, slanting palpebral fissures). On auscultation, both lung fields were clear and no cardiac murmur was heard. Baby was Hypoxemic (saturation is $93.5 \%$ ). He underwent septic workup, was given supportive treatment (oxygen therapy, IV fluid resuscitation) and was started on antibiotics (ampicillin and gentamicin) to cover possible sepsis. Inotropic drugs and injection konakion were started. Whole Blood transfusion was given.

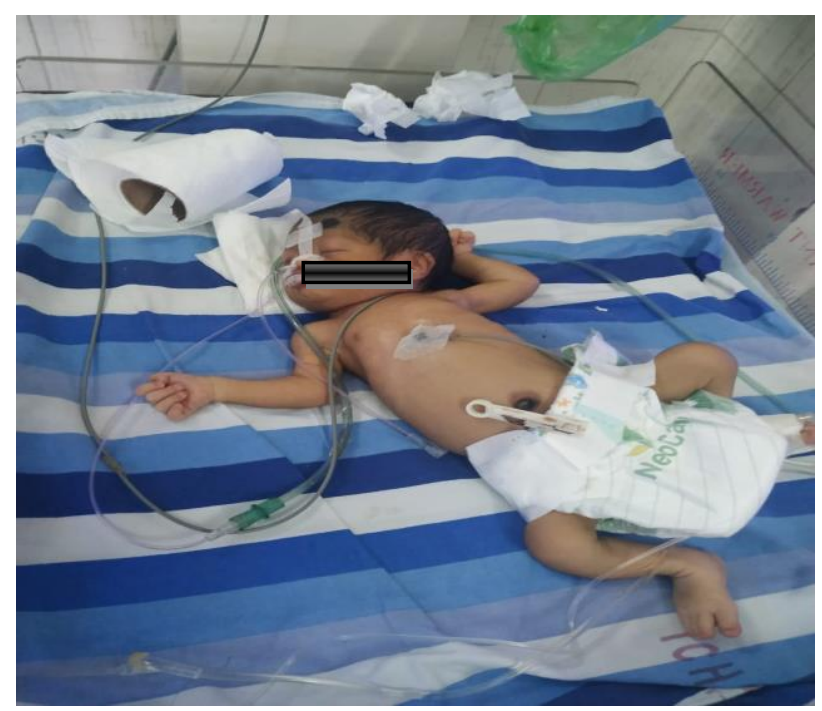

Figure I: Covid-19 in a $7^{\text {th }}$ day Old Baby

Initial laboratory evaluation included a white blood cell count of 37000 cells $/ \mathrm{mm}^{3}$ with $52 \%$ neutrophils, $43 \%$ lymphocytes and hemoglobin was $8.1 \mathrm{~g} / \mathrm{dl}$. Table 1 shows the laboratory values during the hospital course. In light of the community transmission of COVID-19, a nasopharyngeal swab was sent for SARS-CoV-2 PCR testing.

Amikacin was hold as high serum creatinine. At 48 hours of treatment, the baby remained clinically unwell, with repeat hemoglobin of $14.1 \mathrm{~g} / \mathrm{L}$. Antibiotics were changed to cefotaxim. Arrangements were made for transfer to a tertiary care NICU. This baby may be a case of MIS-C or sepsis co-infection with covid-19. We couldn't do other investigations or follow up the case, as we have to refer for ICU support.

Table 1: Laboratory Values during Hospital Course

\begin{tabular}{|l|c|c|}
\hline Investigations & $\mathbf{1 4 . 0 8 . 2 0 2 0}$ & $\mathbf{1 6 . 0 8 . 2 0 2 0}$ \\
\hline Complete blood count & 37 & 19.8 \\
WBC count $\left(\mathrm{x} 10^{3} / \mu \mathrm{L}\right)$ & 8.1 & 14.1 \\
Haemoglobin $(\mathrm{g} / \mathrm{dl})$ & 52 & 60 \\
Neutrophils $(\%)$ & 43 & 33 \\
Lymphocytes $(\%)$ & 260 & 120 \\
Platelets $\left(\mathrm{x} 10^{3} / \mu \mathrm{L}\right)$ & 7.5 & \\
\hline CRP $(\mathrm{C}-$ Reactive Protein) $\mathrm{mg} / \mathrm{dl}$ & & \\
\hline
\end{tabular}




\begin{tabular}{|l|c|l|}
\hline Serum. Sodium(mmol/L) & 140 & \\
\hline Serum potassium(mmol/L) & 5.8 & \\
\hline Serum chloride(mmol/L) & 106 & \\
\hline Prothrombin time(PT) & $14($ control-12) & \\
\hline INR & 1.12 & 1.8 \\
\hline APTT & 125 & \\
\hline Serum Creatinine mg/dl & 1.9 & \\
\hline RT-PCR for COVID 19 & Positive & \\
\hline Chest x-ray normal. & $\begin{array}{c}\text { Showed reduced lung volumes, } \\
\text { but was otherwise normal }\end{array}$ & \\
\hline
\end{tabular}

\section{Case 2}

A 15- day-old female adopted infant was admitted in the SCANU of Dr. M R Khan Shishu Hospital \& ICH on 21.08.2020 with fever, less feeding, and convulsion. The baby was delivered by normal vaginal delivery at home and her mother died after delivery due to PPH. The baby was adopted by a couple since $2^{\text {nd }}$ day of age. Since then she was on artificial feeding. They noticed that the baby did not feed properly for last two days before admission.

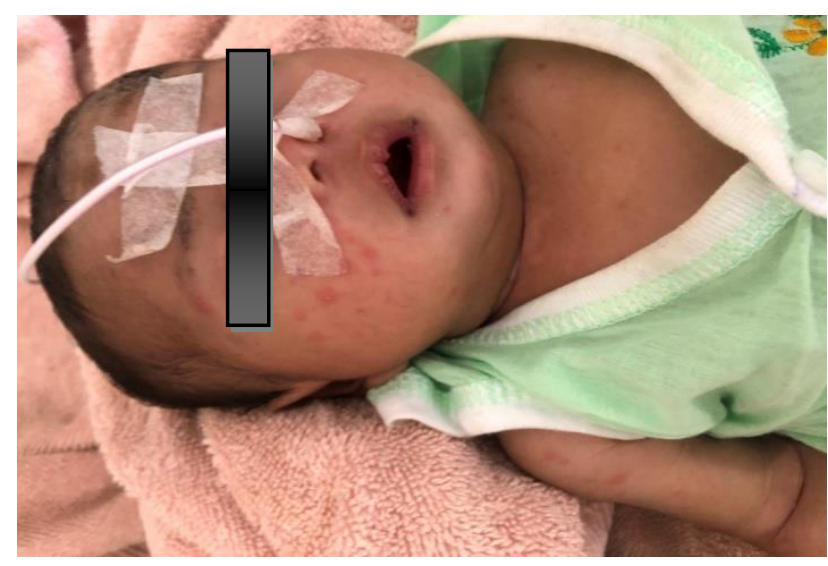

Figure II: COVID 19 in 15 day-old baby

She also developed fever with respiratory distress and developed convulsion for two times. Initial evaluation revealed a temperature of $100^{\circ} \mathrm{F}$ with a

Table 2: Laboratory Values during Hospital Stay heart rate of 190/min. Upon physical examination, the neonate was well appearing without apparent signs of meningitis or sepsis such as apathy, pallor, raised fontanel, except rash at face and prolonged capillary filling. A full evaluation for serious bacterial infection was performed, including culture and laboratory investigations of blood, urine, and CSF. Subsequently, an empirical antibiotic regimen of cefotaxime and amikacin was instituted.To exclude the possibility of community transmission of COVID-19, a nasopharyngeal swab was sent for SARS-CoV-2 PCR testing. Table 2 shows the laboratory values of the baby during the hospital course.

On $3^{\text {rd }}$ day of hospitalization, the RT-PCR report came and it was positive. The patient showed high levels of inflammatory markers, including a Creactive protein (CRP) of $18 \mathrm{mg} / \mathrm{L}$ and d-dimer of $0.52 \mu \mathrm{g} / \mathrm{mL}$ associated with high ferritin (1253 $\mathrm{ng} / \mathrm{mL}$ ). As the temperature was not subsided, the antibiotics were changed to Meropenem and Vancomycin. These antibiotics were continued for 10 days. Again RT-PCR for COVID sent on day $14^{\text {th }}$ and it was found negative. As we have no facility to do antibody testing, with normalization of symptoms and other laboratory tests the baby was discharged on the $15^{\text {th }}$ day of hospitalization. This child recovered with only supportive care and showed complete recovery. The family was advised to self-quarantine to prevent the transmission of COVID-19. We believe that the mode of transmission was horizontal spread from his caregivers.

\begin{tabular}{|l|c|c|c|c|}
\hline Date & $\mathbf{2 3 . 0 8 . 2 0 2 0}$ & $\mathbf{2 6 . 0 8 . 2 0 2 0}$ & $\mathbf{0 1 . 0 9 . 2 0 2 0}$ & $\mathbf{0 6 . 0 9 . 2 0 2 0}$ \\
\hline Complete Blood Count & & & & \\
WBC count $(\mathrm{x} \mathrm{10} / \mu \mathrm{L})$ & 9.6 & & 13 & 13 \\
Hemoglobin $(\mathrm{g} / \mathrm{dl})$ & 19 & & 17 & 16.2 \\
Neutrophils $(\%)$ & 49 & & 56 & 51 \\
Lymphocytes $(\%)$ & 40 & & 29 & 31 \\
\hline
\end{tabular}




\begin{tabular}{|l|c|c|c|c|}
\hline Platelets $\left(\mathrm{x} 10^{3} / \mu \mathrm{L}\right)$ & 295 & & 305 & 160 \\
\hline CRP mg/dL & 18.1 & 4.8 & 6.1 & 1.00 \\
\hline S. Calcium mg/dL & 5.6 & 6.5 & & \\
\hline S. Electrolytes (mmol/L) & & & & \\
S. Sodium & 141 & 143 & & \\
S. Potassium & 6.6 & 3.9 & & \\
S. Chloride & 102 & 103 & & \\
\hline S. Creatinine(mg/dL) & 0.4 & & & \\
\hline SGPT(U/L) & 57 & & & \\
\hline S. Ferritin(ng/mL) & & & & \\
\hline Prothrombin Time(PT) $(\mathrm{sec})$ & & 13 (Control-12) & & \\
\hline INR & 1.04 & & & \\
\hline APTT(sec) & 33 & & & \\
\hline D- Dimer( $\mu \mathrm{g} / \mathrm{mL}$ FEU) & & Positive & & \\
\hline RT-PCR for COVID-19 & & & & \\
\hline Chest x-ray & Pneumonitis & & & \\
& present & & & \\
\hline CSF fluid analysis & $5 \mu / \mathrm{L}$ & & & \\
WBC- & $56 / 80$ & & & \\
Glucose/protein(mg/dL) & Negative & & & \\
Culture & Negative & & & \\
\hline Blood c/s & Negative & & & \\
\hline Urine c/s & & & & \\
\hline
\end{tabular}

\section{Discussion}

Paediatric multisystem inflammatory syndrome temporally associated with COVID-19 (PIMS-TS) or multisystem inflammatory syndrome in children (MIS-C) is an emerging life-threatening nonrespiratory complication of COVID-19 that can present at any time during the course of illness, but commonly at 1 to 6 weeks after infection ${ }^{3-7}$.

The Centers for Disease Control and Prevention (CDC) has declared MIS-C to be a reportable illness as of May 14, 2020, and has recently provided a case definition which includes patients under 21 years of age with fever $\left(>38.0^{\circ} \mathrm{C}\right.$ for $\geq 24$ hours, or report of subjective fever lasting $\geq 24$ hours), laboratory evidence of inflammation [one or more of the following: elevated C-reactive protein (CRP), erythrocyte sedimentation rate (ESR), fibrinogen, procalcitonin, D-dimer, ferritin, lactic acid dehydrogenase (LDH), or interleukin 6 (IL-6), elevated neutrophils, reduced lymphocytes, and low albumin)], severe illness requiring hospitalization, and involvementof two or more organ systems (cardiac, renal, respiratory, hematologic, gastrointestinal, dermatologic, or neurological), with positive testing for SARS-CoV-2 indicating current or recent infection or COVID-19 exposure; and no other alternative plausible diagnoses. ${ }^{2}$ Both of our patient presented with multisystem disease with elevated inflammatory markers. Though $1^{\text {st }}$ case may be co-infection with COVID-19, the $2^{\text {nd }}$ case is consistent with the CDC case definition of MIS-C.

Features of Kawasaki disease- (KD-) like illness of MIS-C were first described in children with 2019 corona virus disease (COVID-19) in the United Kingdom (UK) in late April and a recent study reported children with cardiac involvement and shock of whom one died. ${ }^{7,9}$ that were not outstanding in our patients. Majority of the children with MIS-C in reports thus far showed recovery with response to varying degrees of intensive care, with most requiring respiratory support, inotropes, IVIG (intravenous immunoglobulin) and steroids ${ }^{7-9}$. Similar to the study, our first case presented with circulatory shock and required inotropes and referred for intensive care support.

Case 2 presented with neurologic involvement which has not been observed in published reports thus far. But there was a case report of nosocomial infection with SARS CoV-2 in a one-year old Meningo-encephalitis patient in a tertiary care hospital of Bangladesh ${ }^{10}$. Testing to detect SARSCoV- 2 infection was positive in both patients. The report from Italy described positive testing by RT- 
PCR (reverse-transcription polymerase chain reaction) for SARS-CoV-2 similar to our observation $^{8}$, although in the study from the UK, all children were antibody positive ${ }^{7}$.

Similar to the study from Italy ${ }^{8}$ our $2^{\text {nd }}$ case showed recovery and are being followed up for long term complications. Earlier reports from China and the United States described infants as the most vulnerable pediatric population for severe COVID$19^{11-12}$. Both of our cases were neonate with severe COVID-19.

MIS-C is thought to be related to a post-viral immune-mediated inflammatory process, as suggested by recognition of clinical cases as we move into post-peak phase of COVID-19 illness incidence, although the pathogenesis of the syndrome remains largely unclear ${ }^{2}$.

\section{Conclusion}

We observed features like multisystem inflammatory syndrome in children (MIS-C) in two neonates withSARS-CoV-2 infection, both of them became ill with multisystem involvement. As knowledge about manifestations of COVID-19 in neonate is evolving, reporting is essential which will be helpful for clinicians in recognizing the spectrum of symptoms of MIS-C, which is imperative for timely initiation of appropriate management.

Acknowledgement: To all the stuffs of SCANU of Dr. MR Khan Shishu Hospital \& ICH for their tremendous support in the different stages of treatment of these neonates.

\section{References}

1. Hinojosa-Velasco A, Bobadilla-Montes PV, García-Sosa LE, Mendoza-Durán JG, Pérez-Méndez MJ, Dávila-González $\mathrm{E}$, et al. International Journal of Infectious Diseases 2020;100:21-24

2. Health advisory on multisystem inflammatory syndrome in children (MIS-C) associated with coronavirus disease 2019. Centers for Disease Control and Prevention 2019

3. Jiang L, Tang K, Levin M, Irfan O, Morris K S, Wilson K et al. COVID-19 and multisystem inflammatory syndrome in children and adolescents. Lancet Infectious Diseases 2020

4. Garg RK, Paliwal VK, Gupta A. Encephalopathy in patients with COVID-19: a review. J Med Virol 2020

5. Abdel-Mannan O, Eyre M, Löbel U, Bamford A, Eltze C, Hameed B, et al. Neurologic and radiographic findings associated with covid-19 infection in children. JAMA Neurol 2020

6. Swann OV, Holden KA, Turtle L, Pollock L, Fairfield C J, Drake T M, et al. Clinical characteristics of children and young people admitted to hospital with COVID-19 in United Kingdom: prospective multi-centre observational cohort study. BMJ 2020; 370

7. Riphagen S, Gomez X, Gonzales-Martinez C, Wilkinson N, Theocharis P. Hyper-inflammatory shock in children during COVID-19 pandemic.Lancet 2020;395 (10237):1607-1608

8. Verdoni L, Mazza A, Gervasoni A, Martelli L, Ruggeri M, Ciuffreda $\mathrm{M}$ et al. An outbreak of severe Kawasaki-like disease at the Italian epicentre of the SARS-CoV-2 epidemic: an observational cohort study. TheLancet 2020;395(10239):177178

9. Paediatric multisystem inflammatory syndrome temporally associated with COVID-19. Royal College of Paediatrics and Child Health Guidance 2020. http://www.rcffredpch.ac.uk.

10. Akram A, Jewel MSH, Chowdhury R, Chowdhury MRU, Rahman S. A case report of nosocomial infection with SARS CoV-2 in a one-year old Meningo-encephalitis patient in a tertiary hospital of Bangladesh. Microbes and Infectious Diseases 2020;1(2): 34-38

11. Dong Y, Mo X, Hu Y, Qi X, Jiang F, Jiang Z, et al. Epidemiology of COVID-19 among children in China. Pediatrics 2020; 145(6): 1-12

12. Coronavirus disease 2019 in children United States, February 12-April 2, 2020. Morbidity and Mortality weekly report 2020;69:422-426 